\title{
Polyvinyl alcohol (PVA) molecular weight and extrusion temperature in starch/PVA biodegradable sheets
}

\author{
Juliano Zanela ${ }^{1,2 *}$, Ana Paula Bilckㄹ, Maira Casagrande², Maria Victória Eiras Grossmann ${ }^{1}$ \\ and Fabio Yamashita ${ }^{1}$ \\ ${ }^{1}$ Departamento de Ciência e Tecnologia de Alimentos - DCTA, Centro de Ciências Agrárias - CCA, \\ Universidade Estadual de Londrina - UEL, Londrina, PR, Brasil \\ ${ }^{2}$ Universidade Tecnológica Federal do Paraná - UTFPR, Dois Vizinhos, PR, Brasil \\ *julianozanela@gmail.com
}

\begin{abstract}
The aim of this work was to study the relationship of chain size of partially hydrolyzed PVA blended with starch in properties of biodegradable sheets produced by thermoplastic extrusion. It was also studied the effect of extrusion temperature profile to determine the better PVA chain size and temperature profile to produce biodegradable sheets through a factorial design. The processability and the mechanical, thermal, optical, and microstructural properties of the biodegradable sheets were adequate, indicating that PVA/cassava starch blends have potential to replace conventional non-biodegradable polymers. Tensile strength and Young's modulus ranges from 1.0 to 2.6 and 3.0 to 6.9 MPa respectively, the elongation at break ranges from 42 to $421 \%$. It was not possible to state a conclusive relationship between PVA molecular weight and the materials properties, but in general, PVA with medium molecular weight and high extrusion temperature profile promote an increase of mechanical properties of the sheets.
\end{abstract}

Keywords: calendering, experimental design, mechanical properties.

\section{Introduction}

Petroleum based plastics are used worldwide in a crescent number of application areas, and the disposal of plastics residues is an environmental problem. In the last years, several researchers have studied new eco-friendly materials preferentially from renewable resources to replace conventional petrochemical polymers ${ }^{[1,2]}$.

Starch is one of most studied biopolymer for biodegradable materials production, due to its low cost, biodegradability, and from renewable sources ${ }^{[3]}$, but pure starch presents some drawbacks to replace conventional polymers due to its inherent brittleness, poor mechanical properties, and the hydrophilic character. These drawbacks can be overcome by blending starch with other biodegradable polymers like polyvinyl alcohol - $\mathrm{PVA}^{[4]}$.

PVA is an odorless, nontoxic, water-soluble, and fully biodegradable polymer that presents good film-forming capacity, resistance to greases and oil, good mechanical properties, and good barrier to oxygen and aroma $^{[3]}$.

According to Majdzadeh-Ardakani and Nazari ${ }^{[5]}$, the coprocessing of starch with polar polymers, like PVA, can improve the mechanical properties when compared to pure starch materials, and several studies reported a good compatibility of these polymers in starch/PVA blends. Mao et al. ${ }^{[6]}$ produced sheets by extrusion using cornstarch plasticized with glycerol $(30 \% \mathrm{w} / \mathrm{w})$, with tensile strength of 1.8 MPa and elongation at break of $113 \%$, and adding PVA $(9.1 \% \mathrm{w} / \mathrm{w})$ the tensile strength and elongation at break were enhanced to $4 \mathrm{MPa}$ and $150 \%$ respectively. According to the authors, the material with PVA had no cracks, unlike that observed by SEM in materials without PVA. Similar results was observed by Ray et al..$^{[7]}$, that produced casting films with starch:PVA:glycerol of 60:40:30 and 50:50:30 (wt\%). Films with higher PVA content had better mechanical properties, and the polymers dispersion in the blend was improved, creating a more homogeneous network as observed by SEM and FT-IR. Therefore, PVA and starch have a good compatibility for the production of biodegradable materials.

Zanela et al. ${ }^{[8]}$ produced extruded sheets based on different proportions of starch, PVA and glycerol through a mixture design. The authors observed that all formulations were homogeneous, without visible cracks by SEM, demonstrating a good miscibility between both polymers, and with the increasing, the level of PVA present in the blends, the mechanical and barrier properties of the sheets were increased.

There are several PVA grades, with different molecular weights and chain sizes, due to their large field of application, so it is important to study how these characteristics affect the properties of the films. Limpan et al. ${ }^{[9]}$ evaluate the influence of PVA with different hydrolysis degree and molecular weight in properties of fish myofibrillar protein/PVA blends with glycerol as plasticizer. The author observed that PVA with higher molecular weight improves tensile strength and elongation at break, and PVA with higher hydrolysis degree led to films that were more rigid.

Silva et al. ${ }^{[10]}$ produced films by casting using PVA with different hydrolysis degree and pigskin gelatin, and they observed that the hydrolysis degree influenced the properties 
of the films, but they were unable to find a relationship of the hydrolysis degree with the physical properties of the films.

The goal of this work was to study the relationship of chain size of partially hydrolyzed PVA blended with starch in properties of biodegradable sheets produced by thermoplastic extrusion. It was also studied the effect of extrusion temperature profile to determine the better PVA concentration and temperature profile to produce biodegradable sheets through a factorial design.

\section{Materials and Methods}

\subsection{Materia/s}

It was used three PVA grades (Sekisui Chemical, Japan) with different degrees of hydrolysis (DH) and chain sizes (based on their viscosity in $4 \%$ aqueous solution): Selvol ${ }^{\mathrm{TM}} 203$ (DH: 88.14\%, viscosity $4.10 \mathrm{cP}$ ); Selvol ${ }^{\mathrm{TM}}$ 523 (DH: $87.84 \%$, viscosity: $24.50 \mathrm{cP}$ ) and Selvol ${ }^{\mathrm{TM}}$ 540 (DH: $88.04 \%$, viscosity: $49.40 \mathrm{cP}$ ); native cassava starch (Indemil, Brazil) and glycerol (Dinamica, Brazil).

\subsection{Factorial design}

It was used a $3^{2}$ factorial design with replicate in the central point (total of 10 runs), the independent variables were PVA grade and barrel temperature profile of the five heating zones of the extruder, and the coded and real values for all runs are shown in Table 1.

The factorial designs were analyzed using the Experimental Design proceeding of Statistica 7.0 (Statsoft, USA) software. The 2-way interaction equation (Equation 1) was used to modeling the responses:

$$
\begin{aligned}
& y=\beta_{0}+\beta_{1} x_{1}+\beta_{11} x_{1}^{2}+\beta_{2} x_{2}+\beta_{22} x_{2}^{2}+ \\
& \beta_{12} x_{1} x_{2}+\beta_{122} x_{1} x_{2}^{2}+\beta_{112} x_{1}^{2} x_{2}+\beta_{1122} x_{1}^{2} x_{2}^{2}
\end{aligned}
$$

where: $\mathrm{y}$ is the dependent variable (response); $\beta$ is the regression coefficient of each term; $x_{1}$ is the PVA grade; $x_{2}$ is the extrusion temperature profile.

The desirability function, the relationship between predicted responses on one or more dependent variables and the desirability of responses, was determined using the Experimental Design proceeding of Statistica 7.0 (Statsoft, USA) software.

\subsection{Sheet production}

All the formulations were composed of $38 \mathrm{wt} \%$ of starch, $27 \mathrm{wt} \%$ of PVA and $35 \mathrm{wt} \%$ of glycerol. After manual homogenization, the samples were placed in a vacuum oven (model Q819V2, Quimis, Brazil) with a vacuum pressure of $0.085 \mathrm{MPa}$ for 90 minutes at $85{ }^{\circ} \mathrm{C}$ to incorporate the glycerol using the methodology adapted from Jang and Lee ${ }^{[11]}$. After this step, the blends were extruded in a co-rotating twin screw extruder (model D-20, BGM, Brazil) with a screw diameter of $20 \mathrm{~mm}(\mathrm{~L} / \mathrm{D}=35)$, a screw speed of $100 \mathrm{RPM}$ and a temperature profile according to the experimental design based in Table 1. The samples were extruded using a flat die with $0.8 \mathrm{~mm}$ height and $320 \mathrm{~mm}$ length, coupled with a 3-roll water-cooled calender (AX Plásticos, Brazil) for sheets production.

\subsection{Mechanical properties}

The tensile strength, Young's modulus, and elongation at break were analyzed in a texture analyzer (model TA.XT2i, Stable Micro Systems, England) with an initial distance between the grips of $30 \mathrm{~mm}$ and a crosshead speed of $0.8 \mathrm{~mm} . \mathrm{s}^{-1}$, according to ASTM D882-02 ${ }^{[12]}$ method, with some modifications. Ten samples from each treatment (50 $\mathrm{mm}$ in length and $20 \mathrm{~mm}$ in width) were conditioned in a desiccator with controlled relative humidity and temperature $\left(53 \pm 2 \%\right.$ and $23 \pm 2{ }^{\circ} \mathrm{C}$ respectively) for 72 hours before analysis.

For puncture analysis, ten specimens from each treatment were conditioned as described above and punctured perpendicularly with a $6.35 \mathrm{~mm}$ diameter cylindrical probe at a velocity of $2.0 \mathrm{~mm} \cdot \mathrm{s}^{-1}$. The puncture elongation (mm) was characterized as the maximum elongation supported by the sheet. The puncture strength $(\mathrm{N} / \mathrm{mm})$ was obtained by dividing the maximum force by the sheet thickness.

\subsection{Water Vapor Permeability (WVP)}

Water vapor permeability was determined gravimetrically according to the ASTM E96-009 ${ }^{[13]}$ standard. The measurements were performed using a relative humidity gradient of 33-64\%.

\begin{tabular}{|c|c|c|c|c|}
\hline \multirow{2}{*}{ Formulation } & \multicolumn{2}{|c|}{ Coded value } & \multicolumn{2}{|c|}{ Real value } \\
\hline & PVA Grade $X_{1}$ & Temperature Profile $\mathbf{X}_{2}$ & PVA Grade* $X_{1}$ & Temperature Profile** $X_{2}$ \\
\hline 1 & -1 & -1 & S 203 & $170^{\circ} \mathrm{C}$ \\
\hline 2 & -1 & 0 & S 203 & $190^{\circ} \mathrm{C}$ \\
\hline 3 & -1 & 1 & S 203 & $210^{\circ} \mathrm{C}$ \\
\hline 4 & 0 & -1 & S 523 & $170^{\circ} \mathrm{C}$ \\
\hline 5 & 0 & 0 & S 523 & $190^{\circ} \mathrm{C}$ \\
\hline 6 & 0 & 1 & S 523 & $210^{\circ} \mathrm{C}$ \\
\hline 7 & 1 & -1 & S 540 & $170^{\circ} \mathrm{C}$ \\
\hline 8 & 1 & 0 & S 540 & $190^{\circ} \mathrm{C}$ \\
\hline 9 & 1 & 1 & S 540 & $210^{\circ} \mathrm{C}$ \\
\hline 10 & 0 & 0 & S 523 & $190^{\circ} \mathrm{C}$ \\
\hline
\end{tabular}

Table 1. Coded and real values for $3^{2}$ factorial design.

* S 203: Selvol ${ }^{\mathrm{TM}}$ 203; S 523: Selvol ${ }^{\mathrm{TM}} 523$; $\mathbf{S} \mathbf{5 4 0}$ : Selvol ${ }^{\mathrm{TM}} 540 ; * * \mathbf{1 7 0}^{\circ} \mathbf{C}: 90 / 170 / 170 / 170 / 170{ }^{\circ} \mathrm{C} ; \mathbf{1 9 0}{ }^{\circ} \mathbf{C}: 90 / 170 / 190 / 190 / 190{ }^{\circ} \mathrm{C}$; $210{ }^{\circ} \mathrm{C}: 90 / 170 / 210 / 210 / 210^{\circ} \mathrm{C}$ 


\subsection{Weight Loss in Water (WLW)}

The WLW analysis was performed according to Olivato et al. ${ }^{[14]}$, in triplicate and expressed as the percentage of the original mass (Mi) and the final mass (Mf) of the film after immersion in water for 48 hours at $25^{\circ} \mathrm{C}$, according to Equation 2.

$$
\mathrm{WLW}=\left[\left(\mathrm{M}_{\mathrm{i}}-\mathrm{M}_{\mathrm{f}}\right) / \mathrm{M}_{\mathrm{i}}\right] \times 100
$$

\subsection{Apparent Opacity (Op)}

The Op values of the films were measured according to the method described by Maria et al. ${ }^{[15]}$, using a colorimeter (BYK Gardner, Germany) with illuminant D65 (daylight) and visual angle of $10^{\circ}$. Opacity (Op) was determined as the ratio of the opacity of the sample over a black standard Opb and the opacity over a white standard Opw being represented on an arbitrary scale (0-100\%), and the analyses were performed in triplicate according to Equation 3.

$$
\mathrm{Op}=\left(\mathrm{Op}_{\mathrm{b}} / \mathrm{Op}_{\mathrm{w}}\right) \times 100
$$

\subsection{X-ray Diffraction $(X R D)$}

XRD analysis was performed using a diffractometer (Panalytical X'Pert PRO MPD, Netherlands), emitting copper $\mathrm{K} \alpha$ radiation ( $\lambda=1.5418$ angstrom). The anode radiation was generated at $40 \mathrm{kV}$ and $50 \mathrm{~mA}$ and was monochromatized using a $20 \mathrm{~mA}$ current. Diffraction intensity measurements were performed between $2 \theta=2^{\circ}$ to $60^{\circ}$ at room temperature. The relative crystallinity of each film was calculated by dividing the area of the strongest peaks by the total area of the crystalline region (the total area under the curve minus the baseline).

\subsection{Scanning Electron Microscopy (SEM)}

SEM was recorded using a scanning electron microscope (FEI Quanta 200, USA). The films were fractured in liquid nitrogen, attached to aluminum supports and coated with gold
(BAL-TEC SCD 050 sputter coater, Leica Microsystems, Germany) (40-50 $\mathrm{nm}$ in thickness) at $25^{\circ} \mathrm{C}$ and a pressure of 2.105 Torr for 180 seconds. The surface and the fracture surface of the films were analyzed.

\subsection{Fourier Transform Infrared Spectroscopy (FT-IR)}

The samples were dried over anhydrous calcium chloride salt for one week and analyzed in a Fourier transform infrared spectrophotometer (FT-IR) (IR Prestige 21, Shimadzu, Japan) using a horizontal attenuated total reflection (ATR) module operating over the spectral range of $4000-750 \mathrm{~cm}^{-1}$.

\subsection{Thermogravimetric Analysis (TGA)}

Thermogravimetric analysis was performed using a TGA - 50 (Shimadzu, Japan). The samples were dried over anhydrous calcium chloride salt and analyzed from $25^{\circ} \mathrm{C}$ to $600{ }^{\circ} \mathrm{C}$ with a $10^{\circ} \mathrm{C} \cdot \mathrm{min}^{-1}$ heating rate under a nitrogen atmosphere $\left(20 \mathrm{~mL} \cdot \mathrm{min}^{-1}\right)$.

\section{Results and Discussions}

The sheets of all formulation were continuous and visually homogenous, with a medium thickness of $850 \pm 191 \mu \mathrm{m}$. Most of the equations generated by the mathematical model had coefficients of determination $\left(\mathrm{R}^{2}\right)$ higher than 0.70 , indicating that the models fitted the experimental data well.

\subsection{Mechanical properties}

Table 2 presents the factorial design models (Equation 1) for the mechanical properties of the sheets, Table 3 presents the experimental data, and the values predicted by the model, and Figure 1 presents the response surface plots.

The tensile strength of the sheets ranged from 1.0 to $2.6 \mathrm{MPa}$, and according to the factorial design model the tensile strength was influenced mainly by the PVA grade (Table 2 and Figure 1A), in that the medium chain size PVA(S503) promoted the more resistant material.

Table 2. Factorial design models for the mechanical properties of the biodegradable sheets

\begin{tabular}{cccccc}
\hline Coefficient & $\begin{array}{c}\text { Tensile strength } \\
(\mathbf{M P a})\end{array}$ & $\begin{array}{c}\text { Young's modulus } \\
(\mathbf{M P a})\end{array}$ & $\begin{array}{c}\text { Elongation at break } \\
(\mathbf{\%})\end{array}$ & $\begin{array}{c}\text { Puncture strength } \\
(\mathbf{N} / \mathbf{m m})\end{array}$ & $\begin{array}{c}\text { Puncture elongation } \\
(\mathbf{m m})\end{array}$ \\
\hline$\beta_{0}$ & 1.68 & 4.80 & 184 & 68.54 & 12.75 \\
$\beta_{1}$ & 0.23 & -0.48 & 68 & 11.26 & 4.02 \\
$\beta_{11}$ & 0.43 & $\mathrm{~ns}$ & 91 & 13.43 & 3.35 \\
$\beta_{2}$ & 0.10 & -0.95 & 94 & $\mathrm{~ns}$ & 3.78 \\
$\beta_{22}$ & -0.06 & -1.04 & 29 & -2.95 & 1.0 \\
$\beta_{12}$ & 0.20 & -0.54 & 60 & $\mathrm{~ns}$ & 3.24 \\
$\beta_{122}$ & $\mathrm{~ns}$ & $\mathrm{~ns}$ & $\mathrm{~ns}$ & $\mathrm{~ns}$ & $\mathrm{~ns}$ \\
$\beta_{112}$ & 0.16 & -0.26 & 46 & $\mathrm{~ns}$ & $\mathrm{~ns}$ \\
$\beta_{1122}$ & 0.08 & $\mathrm{~ns}$ & 26 & 0.65 & 0.87 \\
$\mathrm{R}^{2}$ & 0.85 & 0.92 & 0.93 & & 0.94 \\
\hline
\end{tabular}

a $y=\beta_{0}+\beta_{1} x_{1}+\beta_{11} x_{1}^{2}+\beta_{2} x_{2}+\beta_{22} x_{2}^{2}+\beta_{12} x_{1} x_{2}+\beta_{122} x_{1} x_{2}^{2}+\beta_{112} x_{1}^{2} x_{2}+\beta_{1122} x_{1}^{2} x_{2}^{2} ; y=$ response; $x_{1}=$ PVA grade; $x_{2}=$ extrusion temperature profile; $\mathrm{ns}=$ not significant; $\mathrm{R}^{2}=$ Coefficient of determination. 
Table 3. Experimental and predicted data for mechanical properties of the sheets.

\begin{tabular}{|c|c|c|c|c|c|c|c|c|c|c|}
\hline \multirow[t]{2}{*}{ Formulation } & \multicolumn{2}{|c|}{$\begin{array}{c}\text { Tensile strength } \\
\text { (MPa) }\end{array}$} & \multicolumn{2}{|c|}{$\begin{array}{c}\text { Young's modulus } \\
\text { (MPa) }\end{array}$} & \multicolumn{2}{|c|}{$\begin{array}{c}\text { Elongation at break } \\
(\%)\end{array}$} & \multicolumn{2}{|c|}{$\begin{array}{c}\text { Puncture strength } \\
(\mathrm{N} / \mathrm{mm})\end{array}$} & \multicolumn{2}{|c|}{$\begin{array}{c}\text { Puncture elongation } \\
(\mathrm{mm})\end{array}$} \\
\hline & Exp* & Pred & Exp & Pred & Exp & Pred & Exp & Pred & $\operatorname{Exp}$ & Pred \\
\hline 1 & $1.5 \pm 0.2$ & 1.4 & $6.2 \pm 0.9$ & 6.2 & $42 \pm 5$ & 44 & $64 \pm 6$ & 59 & $5.9 \pm 0.3$ & 5.6 \\
\hline 2 & $1.0 \pm 0.1$ & 1.0 & $3.6 \pm 0.2$ & 3.9 & $74 \pm 7$ & 70 & $41 \pm 1$ & 44 & $6.8 \pm 0.2$ & 7.0 \\
\hline 3 & $1.0 \pm 0.1$ & 1.0 & $5.8 \pm 0.3$ & 5.7 & $49 \pm 5$ & 51 & $40 \pm 3$ & 41 & $6.8 \pm 0.1$ & 6.8 \\
\hline 4 & $1.9 \pm 0.2$ & 1.9 & $6.9 \pm 0.3$ & 6.8 & $107 \pm 43$ & 107 & $85 \pm 15$ & 88 & $11.7 \pm 3.0$ & 12.0 \\
\hline 5 & $2.0 \pm 0.3$ & 2.3 & $3.2 \pm 0.2$ & 3.4 & $358 \pm 76$ & 389 & $82 \pm 12$ & 82 & $18.7 \pm 1.7$ & 20.1 \\
\hline 6 & $2.5 \pm 0.2$ & 2.5 & $4.3 \pm 0.3$ & 4.2 & $418 \pm 51$ & 418 & $92 \pm 7$ & 88 & $19.9 \pm 0.6$ & 19.6 \\
\hline 7 & $1.5 \pm 0.1$ & 1.5 & $6.2 \pm 0.3$ & 6.3 & $62 \pm 10$ & 60 & $64 \pm 10$ & 63 & $7.3 \pm 0.7$ & 7.3 \\
\hline 8 & $1.5 \pm 0.1$ & 1.5 & $3.0 \pm 0.2$ & 2.9 & $203 \pm 34$ & 207 & $70 \pm 28$ & 67 & $15.4 \pm 2.0$ & 15.1 \\
\hline 9 & $1.9 \pm 0.1$ & 1.9 & $3.6 \pm 0.1$ & 3.7 & $310 \pm 55$ & 308 & $78 \pm 12$ & 82 & $20.9 \pm 1.1$ & 21.2 \\
\hline 10 & $2.6 \pm 0.2$ & 2.3 & $3.9 \pm 0.3$ & 3.4 & $421 \pm 51$ & 389 & $84 \pm 6$ & 82 & $21.5 \pm 1.0$ & 20.1 \\
\hline
\end{tabular}

*Exp - experimental data; Pred - predicted by the model.
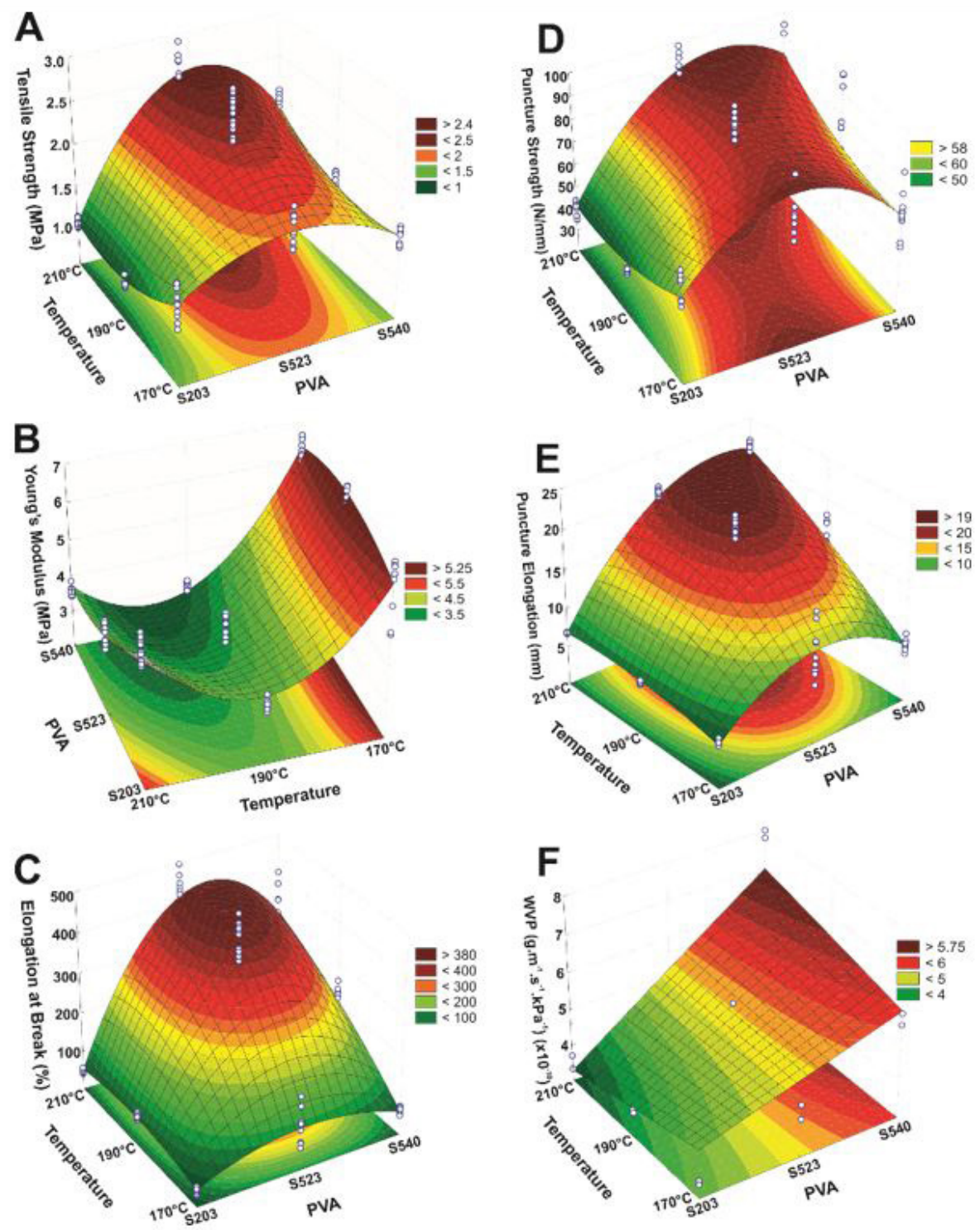

Figure 1. Surface response plot for tensile strength (A); Young's modulus (B); elongation at break (C); puncture strength (D); puncture elongation (E) and water vapor permeability - WVP (F) of the biodegradable sheets. 
The Young's modulus ranged from 3.0 to $6.9 \mathrm{MPa}$, and according to the factorial design model, the modulus was negatively influenced by both the PVA grade and the temperature profile (Table 2 and Figure 1B). According to the model the interaction between PVA and temperature profile of extrusion was negative, i.e., lower temperature profiles increased the values of Young's modulus independent of the PVA grade.

The elongation at break ranged from 42 to $421 \%$, and according to the factorial design model, the elongation was influenced by both the PVA grade and the temperature profile (Table 2 and Figure 1C), and there was a positive interaction between PVA and temperature profile of extrusion. The materials produced with PVA S503 (medial DH) and the higher extrusion temperature profile $\left(90 / 170 / 190 / 190 / 190{ }^{\circ} \mathrm{C}\right)$ presented the higher elongation values.

Mao et al. ${ }^{[6]}$ extruded films of cornstarch (61 wt $\%$ ), PVA (9 wt \%), and glycerol (30 wt \%), and the films had a tensile strength of $4 \mathrm{MPa}$ and elongation at break of $150 \%$ at conditioning humidity of $50 \%$. The PVA used by the authors was similar to S540, and the tensile strength was higher, and the elongation was lower than those obtained in this study. These differences can be attributed to the PVA concentration in the films, because according to Zanela et al. ${ }^{[8]}$ the concentration of PVA was the main factor for increasing the tensile strength, elongation at break and Young modulus of cassava starch/PVA biodegradable sheets.

According to Follain et al. ${ }^{[16]}$, the PVA molecules are stretched and aligned during the extrusion, promoting a good interaction with starch, and higher temperatures enhance these interactions because the PVA reaches the melting temperature. According to Sin et al. ${ }^{\left[{ }^{[17]}\right.}$, the neat PVA (fully hydrolyzed and with medium chain size) has a melting temperature of $207^{\circ} \mathrm{C}$, and when plasticized with 40 parts per hundred parts of resin (phr) of glycerol, the melting point reduces to $177{ }^{\circ} \mathrm{C}$. Therefore, higher temperatures can melt the PVA completely, and the shear forces in extrusion process promoted a better interaction with polymer chains. Thus, these facts explain the tendency of increasing tensile strength and elongation at break of the materials with increasing the extrusion temperature profile.

The puncture strength of the sheets ranged from 40 to $92 \mathrm{~N} / \mathrm{mm}$, and according to the factorial design model, the puncture strength was influenced mainly by the PVA grade (Table 2 and Figure 1D). There was a positive interaction between PVA and temperature profile of extrusion, and the materials produced with intermediate PVA grade level (S503) had the higher puncture strength values.

The puncture elongation ranged from 5.9 to $21.5 \mathrm{~mm}$, and according to the factorial design model the puncture elongation were influenced by both the PVA grade and the temperature profile (Table 2 and Figure 1E), and there was a positive interaction between PVA and temperature profile of extrusion. The material with the higher puncture elongation was produced with PVA S540 $(+1)$ and temperature profile of $90 / 170 / 210 / 210 / 210{ }^{\circ} \mathrm{C}(+1)$.

\subsection{Water Vapor Permeability (WVP)}

The WVP of the sheets ranged from 3.4 to $8.2 \times 10^{-10} \mathrm{~g} \cdot \mathrm{m}^{-1} \cdot \mathrm{s}^{-1} \cdot \mathrm{kPa}^{-1}$, and according to the factorial design model the WVP were influenced mainly by the PVA grade (Table 4 and Figure 1F), and there was a positive interaction between quadratic terms of PVA and temperature profile of extrusion. The sheets with the lower WVP was produced with PVA S203 (-1) and temperature profile of 90/170/210/210/210 ${ }^{\circ} \mathrm{C}(+1)$.

Sheets produced with lower molecular weight PVA had lower WVP, probably because the PVA with lower MW can originate a more compact network with starch, that difficult the transport of water molecules through the polymeric matrix. Limpan et al. ${ }^{[9]}$ had similar results in films produced with fish myofibrillar protein blended with different PVA grades and according to the authors, PVA with higher molecular weight increase the disorder in the amorphous region, promoting an increase in the free volume between the polymer chains.

Zanela et al. ${ }^{\left[{ }^{[8]}\right.}$ obtained WVP values ranging from 3.0 to $8.56 \times 10^{-10} \mathrm{~g} \cdot \mathrm{m}^{-1} \cdot \mathrm{s}^{-1} \cdot \mathrm{kPa}^{-1}$ for cassava starch $/ \mathrm{PVA}$ (S203) sheets using glycerol as plasticizer and PVA ranging from 7.5 to $22.5 \mathrm{wt} \%$. The authors observed that glycerol was the main factor for WVP increasing due to its plasticizer properties. Wang et al. ${ }^{[18]}$ also observed an increase of WVP in casting films of PVA/xylan with high plasticizer content, because glycerol is a small hydrophilic molecule that allows its inclusion between polymers chains, increasing the free volume and so permitting water mobility through the material.

Table 4. Regression coefficients of the factorial design models for water vapor permeability, weight loss in water, and apparent opacity of the biodegradable sheets.

\begin{tabular}{cccc}
\hline Coefficient $^{\text {a }}$ & $\begin{array}{c}\text { Water vapor } \\
\text { permeability } \\
\left(\mathbf{g} \cdot \mathbf{m}^{-1} \cdot \mathbf{s}^{-1} \cdot \mathbf{k P a}^{-1}\right)\left(\mathbf{x} 1 \mathbf{1 0}^{\mathbf{1 0}}\right)\end{array}$ & $\begin{array}{c}\text { Weight loss } \\
\text { in water } \\
\mathbf{( \% )}\end{array}$ & $\begin{array}{c}\text { Apparent } \\
\text { opacity (\%) }\end{array}$ \\
\hline$\beta_{0}$ & 4.99 & 46.66 & 39.52 \\
$\beta_{1}$ & 1.32 & -6.39 & -4.31 \\
$\beta_{11}$ & $\mathrm{~ns}$ & $\mathrm{~ns}$ & -3.20 \\
$\beta_{2}$ & $\mathrm{~ns}$ & $\mathrm{~ns}$ & 3.44 \\
$\beta_{22}$ & $\mathrm{~ns}$ & $\mathrm{~ns}$ & -1.06 \\
$\beta_{12}$ & 0.53 & $\mathrm{~ns}$ & -3.38 \\
$\beta_{122}$ & $\mathrm{~ns}$ & $\mathrm{~ns}$ & $\mathrm{~ns}$ \\
$\beta_{112}$ & $\mathrm{~ns}$ & $\mathrm{~ns}$ & -3.31 \\
$\beta_{1122}$ & 0.84 & $\mathrm{~ns}$ & -1.35 \\
$\mathrm{R} 2$ & 0.71 & 0.62 & 0.82 \\
\hline
\end{tabular}

${ }^{a} y=\beta_{0}+\beta_{1} x_{1}+\beta_{11} x_{1}^{2}+\beta_{2} x_{2}+\beta_{22} x_{2}^{2}+\beta_{12} x_{1} x_{2}+\beta_{122} x_{1} x_{2}^{2}+\beta_{112} x_{1}^{2} x_{2}+\beta_{1122} x_{1}^{2} x_{2}^{2}$, $y=$ response; $x_{1}=$ PVA grade; $x_{2}=$ extrusion temperature profile; $\mathrm{ns}=$ not significant; $\mathrm{R}^{2}=$ Coefficient of determination. 


\subsection{Weight Loss in Water (WLW)}

The WLW of the sheets ranged from 36.2 to $55.4 \%$, and according to the factorial design model, the WLW was influenced negatively only by the PVA grade (Table 4). The PVA with higher chain size reduced the material solubility, and according to the manufacturer ${ }^{[19]}$, this behavior is typical of PVA.

Limpan et al. ${ }^{[9]}$ observed the same behavior, but the factor of major influence in films solubility was the PVA hydrolysis degree. The surface plot of WLW is shown in Figure 2A.

According to Zanela et al. ${ }^{[20]}$, the high WLW can be important for biodegradable sheets, accelerating the biodegradation process when these materials are discarded in the aquatic environment for example.

\subsection{Apparent opacity (Op)}

The Op analysis ranged from 29.1 to $55.3 \%$ (Table 5), and according to the factorial design model the Op was influenced negatively by PVA grade and positively by the linear coefficient of temperature profile (Table 4 and Figure 2B), and the interaction between PVA and temperature profile of extrusion was negative. The sheets produced with
PVA S203 were more opaque than those with PVA S523, for all extrusion temperatures.

Maria et al. ${ }^{[15]}$ produced casting films with gelatin/PVA/glycerol and they did not find a relationship with Op and PVA grade (hydrolysis degree and molecular weight). The values of Op reported were lower than those obtained in this study, probably because films are thinner than sheets, and the casting process leads to more transparent materials than extrusion. Besides that, the high temperatures in extrusion can degrade some compounds and/or induce non-enzymatic reactions, resulting in yellowish sheets that present greater difference when compared to casting films.

\subsection{X-Ray Diffraction (XRD)}

The biodegradables sheets of all formulations presented similar diffractograms (Figure 3), with a sharp peak at $19.9^{\circ}$, and an overlapped peaks at $17.7^{\circ}$ and $23.5^{\circ}$, similar to observed by Zanela et al. ${ }^{[8]}$, and a diffraction peak at $40.6^{\circ}$. Das et al. ${ }^{[21]}$ produced starch:PVA film and they attributed the $19.6^{\circ}$ peak to the ordered arrangement of PVA chains in the material, and the $17.7^{\circ}$ peak was attributed to plasticized starch, but this peak had little intensity, and it was overlapped by the peak at $19.9^{\circ}$.
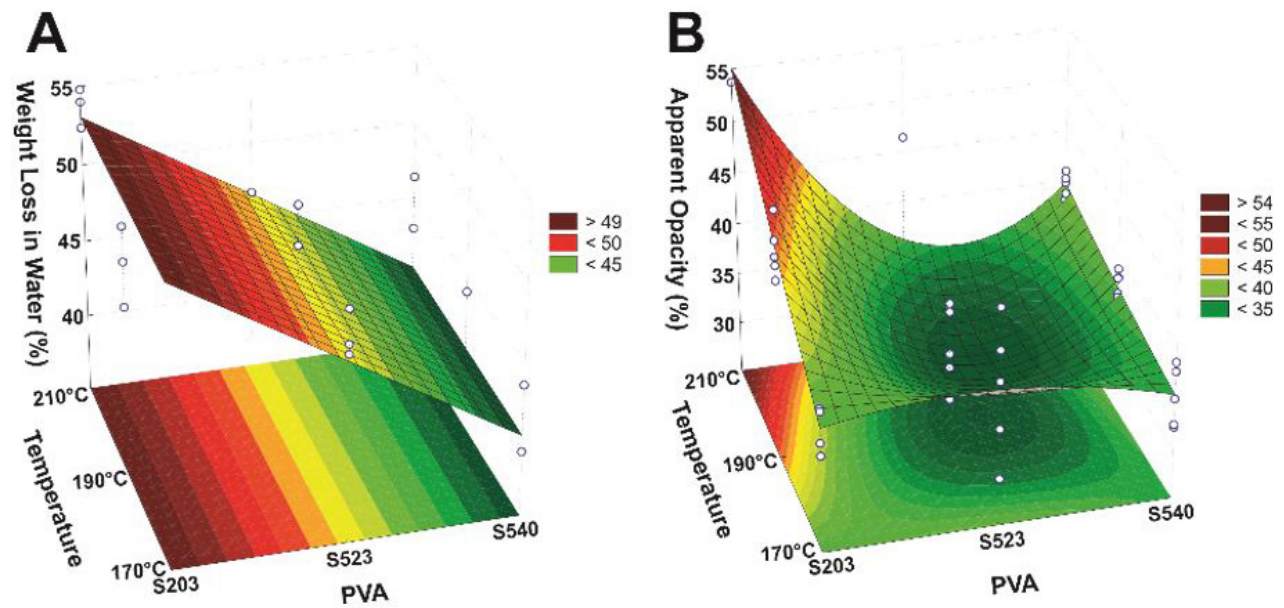

Figure 2. Surface response plot for weight loss in water - WLW (A) and apparent opacity (B) of the biodegradable sheets.

Table 5. Experimental data and predicted values by the factorial design model for water vapor permeability, weight loss in water, apparent opacity and crystallinity index of the biodegradable sheets.

\begin{tabular}{|c|c|c|c|c|c|c|c|}
\hline \multirow{2}{*}{ Formulation } & \multicolumn{2}{|c|}{ WVP $\left(x 10^{10}\right)^{a}$} & \multicolumn{2}{|c|}{ Weight loss in water $(\%)$} & \multicolumn{2}{|c|}{ Apparent opacity (\%) } & \multirow{2}{*}{$\begin{array}{c}\text { Crystallinity } \\
\text { Index (\%) }\end{array}$} \\
\hline & Obs $^{\mathrm{b}}$ & Pred & Obs & Pred & Obs & Pred & \\
\hline 1 & $3.4 \pm 0.1$ & 4.3 & $55.4 \pm 0.2$ & 53.0 & $37.2 \pm 2.1$ & 37.0 & 21.2 \\
\hline 2 & $3.4 \pm 0.1$ & 3.8 & $48.7 \pm 2.6$ & 53.0 & $45.3 \pm 2.6$ & 45.8 & 21.4 \\
\hline 3 & $3.5 \pm 0.3$ & 3.3 & $53.7 \pm 1.2$ & 53.0 & $55.3 \pm 1.1$ & 55.1 & 21.7 \\
\hline 4 & $4.2 \pm 0.3$ & 5.2 & $48.2 \pm 1.5$ & 46.7 & $38.1 \pm 6.4$ & 38.1 & 20.0 \\
\hline 5 & $5.2 \pm 0.6$ & 5.2 & $46.8 \pm 3.7$ & 46.7 & $33.7 \pm 3.7$ & 31.4 & 20.6 \\
\hline 6 & $4.5 \pm 0.1$ & 5.2 & $46.3 \pm 0.5$ & 46.7 & $36.2 \pm 5.7$ & 36.2 & 20.8 \\
\hline 7 & $5.7 \pm 0.2$ & 5.9 & $36.2 \pm 9.1$ & 40.3 & $35.0 \pm 2.9$ & 35.2 & 20.7 \\
\hline 8 & $5.0 \pm 0.2$ & 6.5 & $41.0 \pm 2.7$ & 40.3 & $37.6 \pm 1.2$ & 37.1 & 20.4 \\
\hline 9 & $7.9 \pm 0.1$ & 7.0 & $42.3 \pm 4.4$ & 40.3 & $39.5 \pm 1.2$ & 39.7 & 21.5 \\
\hline 10 & $8.2 \pm 0.1$ & 5.2 & $48.0 \pm 3.2$ & 46.7 & $29.1 \pm 0.8$ & 31.4 & 21.9 \\
\hline
\end{tabular}

${ }^{\mathrm{a}} \mathrm{WVP}-$ Water vapor permeability $\left(\mathrm{g} \cdot \mathrm{m}^{-1} \cdot \mathrm{s}^{-1} \cdot \mathrm{kPa}^{-1}\right) ;{ }^{\mathrm{b}}$ Obs - experimental data; Pred -predicted by the model. 
According to Moorthy ${ }^{[22]}$, cassava starch presents diffraction pattern $\mathbf{A}, \mathbf{C}$ or a mixture of them, and three major peaks were observed in $15.3,17.1$ and $23.5^{\circ}$, but these peaks were not seen in our diffractograms, and probably they were overlapped by the $19.9^{\circ}$ sharp peak.

The crystallinity index ranges from 20.0 to $21.9 \%$ according to Table 5 . The starch crystallinity could be originated from the retrogradation of starch after the extrusion process or, according to Li et al. ${ }^{[23]}$ the crystallinity structure could be due to the native crystallinity that remains after the extrusion, but the crystallinity of the sheets can be attributed mainly to PVA.

\subsection{Scanning Electron Microscopy (SEM)}

Figure 4 shows the SEM analysis of the fracture of the biodegradable sheets, and it is possible to observe a smooth surface, without cracks and domains, due to the good compatibility of both polymers. Similar results was reported by Priya et al. ${ }^{[24]}$ for PVA:cornstarch casting film, and by Maiti et al. ${ }^{[25]}$, for casting starch:PVA films. It was not possible to observe differences in microstructure promoted by temperature or PVA grade used.

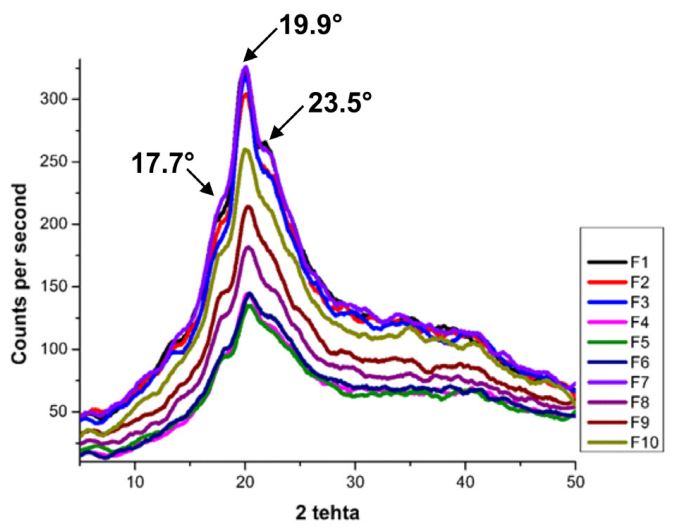

Figure 3. Diffractograms of the starch-PVA biodegradable sheets (F1-F10, formulations according to Table 1).

\subsection{Fourier Transform Infrared Spectroscopy (FT-IR)}

The FT-IR spectra of the biodegradable sheets are shown in Figure 5, and it is possible to observe that all sheets presented similar spectra.

The region near $3300 \mathrm{~cm}^{-1}$ is related to the hydroxyl $(\mathrm{O}-\mathrm{H})$ stretching assigned to molecular and intermolecular hydrogen bonding. The vibration region between $3000-2800 \mathrm{~cm}^{-1}$ is due to the $(\mathrm{C}-\mathrm{H})$ stretching, and it is in agreement with observed by Singha and Kapoor ${ }^{[2]}$, in potato starch:PVA blends produced by casting. According to Mansur et al. ${ }^{[26]}$, the spectral range between $1750-1735 \mathrm{~cm}^{-1}$ is assigned to the stretching of $\mathrm{C}-\mathrm{O}$ and $\mathrm{C}=\mathrm{O}$ groups present in residual acetate groups of PVA molecules. The band at $1275 \mathrm{~cm}^{-1}$ is due to the secondary alcohol present in PVA structure. Similar results were observed by Brandelero et al. ${ }^{[27]}$, and Imam et al. ${ }^{[28]}$ in films based on cassava starch:PVA and cornstarch:PVA respectively.

\subsection{Thermogravimetric Analysis (TGA)}

Figure 6 presents the weight loss versus temperature curves of the biodegradable sheets, and the weight loss occurred between $150-450{ }^{\circ} \mathrm{C}$ and the main weight loss was around $300{ }^{\circ} \mathrm{C}(61.8$ to $53.5 \%)$, and these results are similar to those reported by Zanela et al. ${ }^{[20]}$.

The DTG curves (Figure 6) show three main steps of degradation, occurring around 250,320 and $440^{\circ} \mathrm{C}$, respectively. According to Rahman et al. ${ }^{[2]}$, the degradation of starch:PVA blends plasticized with glycerol can be divided into three phases. The first phase is below $200{ }^{\circ} \mathrm{C}$, that involves the vaporization of volatiles substances, for example, water. The second phase occurs between $200-500{ }^{\circ} \mathrm{C}$ and is related to boiling of glycerol $\left(290{ }^{\circ} \mathrm{C}\right)$, and severe degradation of the main chain, lateral groups, and depolymerization producing small hydrocarbon degradation products, like alkenes, alkanes, and aromatics with posterior vaporization of degradation products. The third phase occurs above $500^{\circ} \mathrm{C}$ and corresponds to the carbonization of the organic matter.

According to the TGA analysis, it was not possible to observe a distinct pattern between each PVA grade and extrusion temperature profile, because all the curves were similar, indicating that neither the PVA grade nor the temperature profile of the extruder influenced the thermal behavior of the biodegradable sheets.

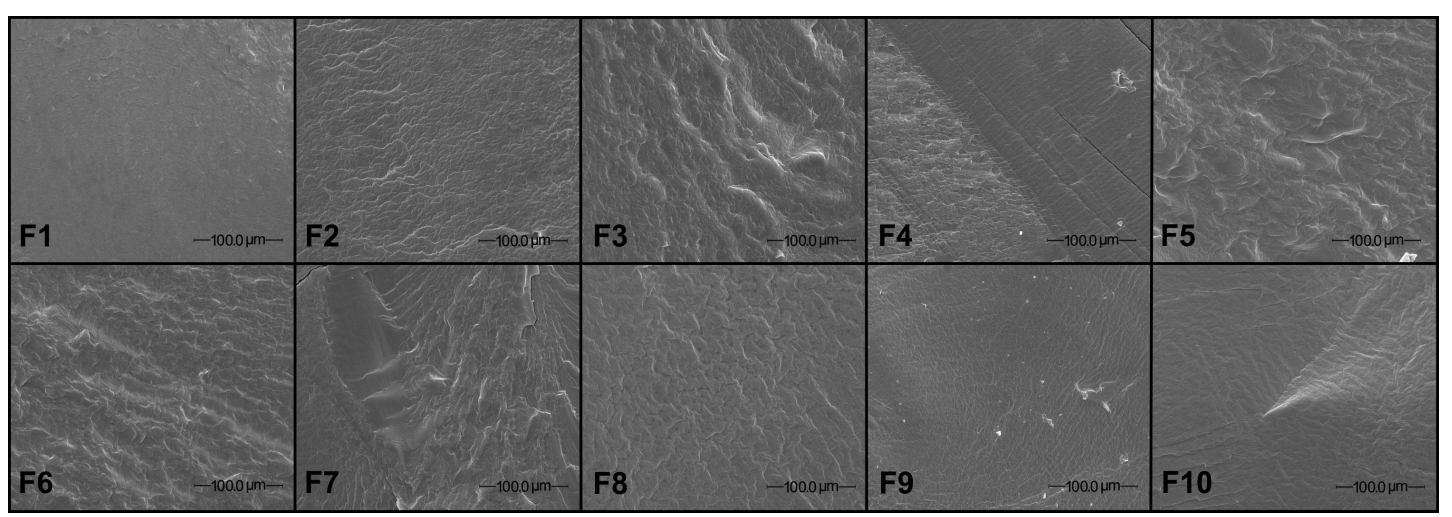

Figure 4. Scanning electron microscopy micrographs of the fracture of the sheets with magnification at $800 \mathrm{x}$ (F1-F10, formulations according to Table 1). 


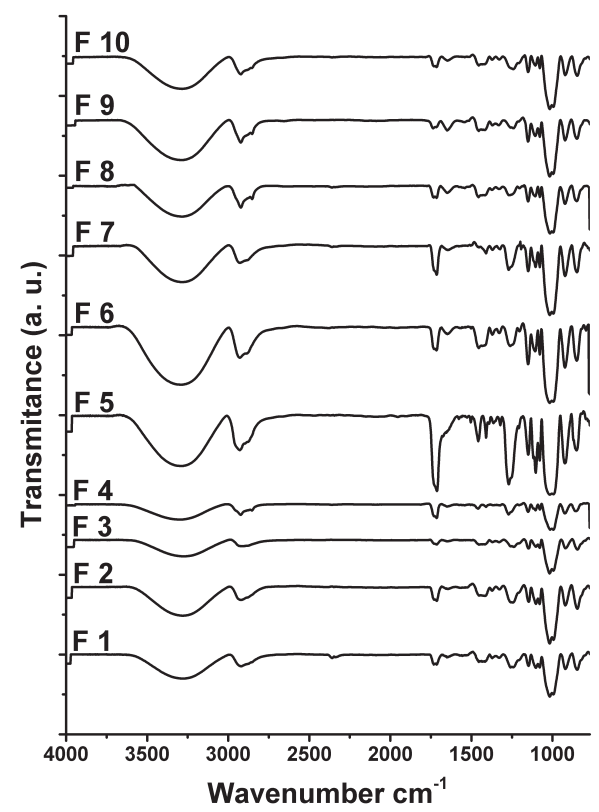

Figure 5. FT-IR analysis of the starch-PVA biodegradable sheets (F1-F10, formulations according to Table 1).
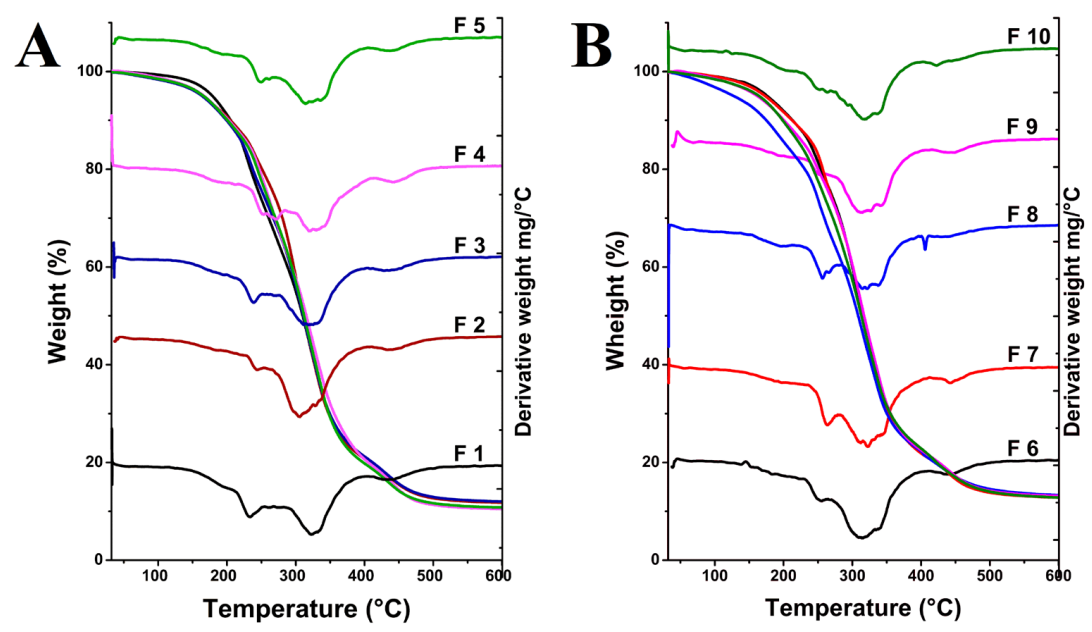

Figure 6. TGA and DTG analysis of the starch-PVA biodegradable sheets (F1-F10, formulations according to Table 1).

\section{Conclusions}

The biodegradable sheets presented good processability, mechanical, thermal, optical, and microstructural properties; characterizing the interaction between the PVA and the cassava starch and indicating the potential for replacement of conventional non-biodegradable polymers for specific uses, e.g., when water resistance or high transparency was not necessary.

It was not possible to state a conclusive relationship between PVA molecular weight and the materials properties, but in general, PVA with medium molecular weight and high extrusion temperature profile promote an increase of mechanical properties of the sheets in the conditions tested.

\section{Acknowledgements}

The authors thank the multi-user Laboratories at Londrina State University (UEL) for the X-ray diffraction analysis (LARX), FT-IR and thermal analysis (ESPEC), and scanning electron microscopy (LMEM). The authors also thank the Federal University of Technology - Parana (UTFPR), the National Council for Scientific and Technological Development (CNPq) and the Araucaria Foundation (Fundação Araucaria) for their financial support. 


\section{References}

1. Park, H. R., Chough, S. H., Yun, Y. H., \& Yoon, S. D. (2005). Properties of starch/PVA blend films containing citric acid as additive. Journal of Polymers and the Environment, 13(4), 375-382. http://dx.doi.org/10.1007/s10924-005-5532-1.

2. Singha, A. S., \& Kapoor, H. (2014). Effects of plasticizer/ cross-linker on the mechanical and thermal properties of starch/ PVA blends. Iranian Polymer Journal, 23(8), 655-662. http:// dx.doi.org/10.1007/s13726-014-0260-9.

3. Tang, X., \& Alavi, S. (2011). Recent advances in starch, polyvinyl alcohol based polymer blends, nanocomposites and their biodegradability. Carbohydrate Polymers, 85(1), 7-16. http://dx.doi.org/10.1016/j.carbpol.2011.01.030.

4. Aydin, A. A., \& Ilberg, V. (2016). Effect of different polyol-based plasticizers on thermal properties of polyvinyl alcohol:starch blends. Carbohydrate Polymers, 136, 441-448. http://dx.doi. org/10.1016/j.carbpol.2015.08.093. PMid:26572374.

5. Majdzadeh-Ardakani, K., \& Nazari, B. (2010). Improving the mechanical properties of thermoplastic starch/poly(vinyl alcohol)/clay nanocomposites. Composites Science and Technology, 70(10), 1557-1563. http://dx.doi.org/10.1016/j. compscitech.2010.05.022

6. Mao, L., Imam, S., Gordon, S., Cinelli, P., \& Chiellini, E. (2000). Extruded cornstarch - glycerol - polyvinyl alcohol blends: mechanical properties, morphology, and biodegradability. Journal of Polymers and the Environment, 8(4), 205-211. http://dx.doi.org/10.1023/A:1015201928153.

7. Ray, D., Roy, P., Sengupta, S., Sengupta, S. P., Mohanty, A. K., \& Misra, M. (2009). A study of physicomechanical and morphological properties of starch/poly(vinylalcohol) based films. Journal of Polymers and the Environment, 17(1), 56-63. http://dx.doi.org/10.1007/s10924-009-0117-z.

8. Zanela, J., Shirai, M. A., Reis, M. O., Mali, S., Grossmann, M. V. E., \& Yamashita, F. (2015). Mixture design to develop biodegradable sheets with high levels of starch and polyvinyl alcohol. Starch, 67(11-12), 1011-1019. http://dx.doi.org/10.1002/ star.201500094.

9. Limpan, N., Prodpran, T., Benjakul, S., \& Prasarpran, S. (2012). Influences of degree of hydrolysis and molecular weight of poly(vinyl alcohol) (PVA) on properties of fish myofibrillar protein/PVA blend films. Food Hydrocolloids, 29(1), 226-233. http://dx.doi.org/10.1016/j.foodhyd.2012.03.007.

10. Silva, G. G. D., Sobral, P. J. A., Carvalho, R. A., Bergo, P. V. A., Mendieta-Taboada, O., \& Habitante, A. M. Q. B. (2008). Biodegradable films based on blends of gelatin and poly (vinyl alcohol): effect of PVA type or concentration on some physical properties of films. Journal of Polymers and the Environment, 16(4), 276-285. http://dx.doi.org/10.1007/s10924-008-0112-9.

11. Jang, J., \& Lee, D. K. (2003). Plasticizer effect on the melting and crystallization behavior of polyvinyl alcohol. Polymer, 44(26), 8139-8146. http://dx.doi.org/10.1016/j.polymer.2003.10.015.

12. American Society for Testing and Materials-ASTM. (2002). ASTM D882-02: standard test methods for tensile properties of thin plastic sheeting. West Conshohocken: ASTM. http:// dx.doi.org/10.1520/D0882-12.

13. American Society for Testing and Materials - ASTM. (2000). ASTM E96: standard test methods for water vapor transmission of materials. West Conshohocken: ASTM. http://dx.doi. org/10.1520/E0096_E0096M-16.

14. Olivato, J. B., Grossmann, M. V. E., Bilck, A. P., \& Yamashita, F. (2012). Effect of organic acids as additives on the performance of thermoplastic starch/polyester blown films. Carbohydrate Polymers, 90(1), 159-164. http://dx.doi.org/10.1016/j. carbpol.2012.05.009. PMid:24751025.
15. Maria, T. M. C., Carvalho, R. A., Sobral, P. J. A., Habitante, A. M. B. Q., \& Solorza-Feria, J. (2008). The effect of the degree of hydrolysis of the PVA and the plasticizer concentration on the color, opacity, and thermal and mechanical properties of films based on PVA and gelatin blends. Journal of Food Engineering, 87(2), 191-199. http://dx.doi.org/10.1016/j. jfoodeng.2007.11.026.

16. Follain, N., Joly, C., Dole, P., \& Bliard, C. (2005). Properties of starch based blends. Part 2. Influence of poly vinyl alcohol addition and photocrosslinking on starch based materials mechanical properties. Carbohydrate Polymers, 60(2), 185192. http://dx.doi.org/10.1016/j.carbpol.2004.12.003.

17. Sin, L. T., Aizan, W., Abdul, W., \& Rahmat, A. R. (2010). Specific heats of neat and glycerol plasticized polyvinyl alcohol. Pertanika Journal of Science \& Technology, 18(2), 387-391. Retrieved in 2017, May 31, from http://www.pertanika.upm. edu.my/Pertanika\%20PAPERS/JST\%20Vol.\%2018\%20(2)\%20 Jul.\%202010/17\%20Pg\%20387-391.pdf

18. Wang, S., Ren, J., Kong, W., Gao, C., Liu, C., Peng, F., \& Sun, R. (2014). Influence of urea and glycerol on functional properties of biodegradable PVA / xylan composite films. Cellulose, 21(1), 495-505. http://dx.doi.org/10.1007/s10570013-0091-4.

19. Sekisui Chemical Co. (2016, november 22). Selvol TM polyvinyl alcohol. Calvert City. Retrieved in 2017, May 31, from http:// www.sekisui-sc.com/products/polyvinyl-alcohol

20. Zanela, J., Olivato, J. B., Dias, A. P., Grossmann, M. V. E., \& Yamashita, F. (2015). Mixture design applied for the development of films based on starch, polyvinyl alcohol, and glycerol. Journal of Applied Polymer Science, 132(43), 42697. http://dx.doi.org/10.1002/app.42697.

21. Das, K., Ray, D., Bandyopadhyay, N. R., Gupta, A., Sengupta, S., Sahoo, S., Mohanty, A., \& Misra, M. (2010). Preparation and characterization of cross-linked starch/poly(vinyl alcohol) green films with low moisture absorption. Industrial \& Engineering Chemistry Research, 49(5), 2176-2185. http:// dx.doi.org/10.1021/ie901092n.

22. Moorthy, S. N. (2002). Physicochemical and functional properties of tropical tuber starches: a review. Stärke, 54(12), 559-596. http://dx.doi.org/10.1002/1521-379X(200212)54:12<559::AIDSTAR2222559>3.0.CO;2-F.

23. Li, M., Hasjim, J., Xie, F., Halley, P. J., \& Gilbert, R. G. (2014). Shear degradation of molecular, crystalline, and granular structures of starch during extrusion. Starch, 66(7-8), 595-605. http://dx.doi.org/10.1002/star.201300201.

24. Priya, B., Gupta, V. K., Pathania, D., \& Singha, A. S. (2014). Synthesis, characterization and antibacterial activity of biodegradable starch/PVA composite films reinforced with cellulosic fibre. Carbohydrate Polymers, 109, 171-179. http:// dx.doi.org/10.1016/j.carbpol.2014.03.044. PMid:24815414.

25. Maiti, S., Ray, D., \& Mitra, D. (2012). Role of Crosslinker on the Biodegradation Behavior of Starch/Polyvinylalcohol Blend Films. Journal of Polymers and the Environment, 20(3), 749-759. http://dx.doi.org/10.1007/s10924-012-0433-6.

26. Mansur, H. S., Sadahira, C. M., Souza, A. N., \& Mansur, A. A. P. (2008). FTIR spectroscopy characterization of poly (vinyl alcohol) hydrogel with different hydrolysis degree and chemically crosslinked with glutaraldehyde. Materials Science and Engineering C, 28(4), 539-548. http://dx.doi.org/10.1016/j. msec.2007.10.088.

27. Brandelero, R. P. H., Yamashita, F., Zanela, J., Brandelero, E. M., \& Caetano, J. G. (2015). Mixture design applied to evaluating the effects of polyvinyl alcohol (PVOH) and alginate on the properties of starch-based films. Stärke, 67(1-2), 191-199. http://dx.doi.org/10.1002/star.201400119. 
28. Imam, S. H., Cinelli, P., Gordon, S. H., \& Chiellini, E. (2005). Characterization of biodegradable composite films prepared from blends of poly(vinyl alcohol), cornstarch, and lignocellulosic fiber. Journal of Polymers and the Environment, 13(1), 47-55. http://dx.doi.org/10.1007/s10924-004-1215-6.

29. Rahman, W. A. W. A., Sin, L. T., Rahmat, A. R., \& Samad, A. A. (2010). Thermal behaviour and interactions of cassava starch filled with glycerol plasticized polyvinyl alcohol blends. Carbohydrate Polymers, 81(4), 805-810. http://dx.doi. org/10.1016/j.carbpol.2010.03.052.

Received: May 31, 2017 Revised: Sept. 07, 2017 Accepted: Oct. 18, 2017 